\title{
The effect of thermal annealing on the optical properties of Mg-doped zincblende GaN epilayers
}

DOI:

$10.1063 / 5.0057824$

Document Version

Accepted author manuscript

Link to publication record in Manchester Research Explorer

\section{Citation for published version (APA):}

Dyer, D., Church, S., Jain, M., Kappers, M. J., Frentrup, M., Wallis, D., Oliver, R. A., \& Binks, D. (2021). The effect of thermal annealing on the optical properties of Mg-doped zincblende GaN epilayers. Journal of Applied Physics, 130(8), [085705]. https://doi.org/10.1063/5.0057824

\section{Published in:}

Journal of Applied Physics

\section{Citing this paper}

Please note that where the full-text provided on Manchester Research Explorer is the Author Accepted Manuscript or Proof version this may differ from the final Published version. If citing, it is advised that you check and use the publisher's definitive version.

\section{General rights}

Copyright and moral rights for the publications made accessible in the Research Explorer are retained by the authors and/or other copyright owners and it is a condition of accessing publications that users recognise and abide by the legal requirements associated with these rights.

\section{Takedown policy}

If you believe that this document breaches copyright please refer to the University of Manchester's Takedown Procedures [http://man.ac.uk/04Y6Bo] or contact uml.scholarlycommunications@manchester.ac.uk providing relevant details, so we can investigate your claim.

\section{OPEN ACCESS}




\title{
The effect of thermal annealing on the optical properties of Mg-doped zincblende GaN epilayers
}

\author{
D. Dyer ${ }^{1}$, S. A. Church ${ }^{1}$, M. Jain ${ }^{2}$, M. J. Kappers ${ }^{3}$, M. Frentrup ${ }^{3}$, D. J. Wallis ${ }^{2-4}$, R. A. Oliver ${ }^{3}$ and \\ D. J. Binks ${ }^{1, a)}$ \\ ${ }^{I}$ Department of Physics and Astronomy \& Photon Science Institute, University of Manchester, \\ Manchester, M13 9PL, United Kingdom \\ ${ }^{2}$ Kubos Semiconductors Ltd. Future Business Park, Cambridge, CB4 2HY, United Kingdom \\ ${ }^{3}$ Department of Materials Science and Metallurgy, University of Cambridge, Cambridge, CB3 OFS, \\ United Kingdom \\ ${ }^{4}$ Centre for High Frequency Engineering, University of Cardiff, Cardiff, CF24 3AA, United Kingdom \\ ${ }^{a)}$ Author to whom correspondences should be addressed: david.binks@ manchester.ac.uk
}

The effects of thermal annealing on the optical properties of $\mathrm{Mg}$-doped cubic zinc-blende $\mathrm{GaN}$ epilayers grown by metalorganic chemical vapor deposition on $3 \mathrm{C}-\mathrm{SiC} / \mathrm{Si}(001)$ substrates are investigated. The photoluminescence spectra show near band edge features and a blue luminescence band that depend on $\mathrm{Mg}$ concentration, temperature and excitation power density. Annealing the sample in a $\mathrm{N}_{2}$ atmosphere causes the intensity of the blue band to increase by a factor of 5 . Power dependent photoluminescence measurements show a reduction in the laser excitation density required for saturation of the blue band after annealing, indicating an increase in the recombination lifetime. Time decay measurements confirm this increase, which is attributed to a reduction in the concentration of non-radiative defects after annealing. The results presented here are compared to those reported previously for $\mathrm{Mg}$-doped hexagonal wurtzite GaN.

\section{Introduction}

Light-emitting diodes (LEDs) based on InGaN/GaN quantum wells (QWs) grown in the wurtzite (wz) crystal phase emit light in the blue spectral region with an external quantum efficiency (EQE) $>80 \%$, and are used in combination with a yellow phosphor as the basis of efficient LED lighting ${ }^{1,2}$. However, producing white light by combining separate red, green and blue LEDs would avoid the Stokes' loss inherent to the use of the phosphor and also enable more control over the emitted spectrum of the lighting. Whilst efficient redemitting LEDs based on III-phosphide materials are available, intrinsic green-emitting devices with sufficient efficiency have not yet been produced - an issue which has become known as the "green-gap",2,3. Green emission can be obtained from InGaN/GaN QWs by increasing the indium fraction, but these devices have significantly reduced efficiency compared to their blue-emitting counterparts, having EQE's of typically $20-50 \%^{1}$ depending on the specific emission wavelength. There have been several mechanisms suggested for this reduction in efficiency ${ }^{1,3,4}$. The higher indium content needed to get into the green spectral region increases the polarisation fields across the QW, which reduces the electron-hole overlap and thus the rate of radiative recombination. Also, the higher indium content is achieved by growing the $\mathrm{QW}$ at a lower temperature, resulting in a higher concentration of point defects that act as centres of nonradiative recombination ${ }^{4}$. Thus, overall, nonradiative recombination competes more successfully with radiative recombination in green wz QWs than their blue counterparts.

The zinc-blende $(\mathrm{zb})$ crystal structure is an alternative $\mathrm{GaN}$ phase, which does not produce polarisation fields across the $\mathrm{QW}$, and the consequent reduction in radiative rate, when grown along the [001] direction ${ }^{5}$. It also has a smaller bandgap than $\mathrm{wz}^{-\mathrm{GaN}^{6}}$, so that a smaller indium fraction is required to achieve green emission, despite the absence of the 
quantum confined Stark effect ${ }^{7}$. This allows higher InGaN growth temperatures to be used thus decreasing the density of non-radiative recombination centres.

The p-type layer used in GaN-based LEDs is typically produced by doping with $\mathrm{Mg}$, the effects of which have been investigated thoroughly for $\mathrm{wz}^{-\mathrm{GaN}^{8-16}}$. Passivation is a common problem in metalorganic chemical vapor deposition (MOCVD) grown Mg-doped $\mathrm{GaN}$ and occurs when hydrogen introduced during growth forms electrically inactive complexes with $\mathrm{Mg}$. These complexes must be dissociated for the material to be p-type $e^{9,16}$, which is typically achieved by post-growth thermal annealing?

Reports of Mg-doped zb-GaN have so far been limited. Molecular beam epitaxy (MBE) grown layers have been studied on both GaAs and $\mathrm{SiC} / \mathrm{Si}$ substrates and characterised by photoluminescence (PL) and Hall effect measurements ${ }^{17-22}$. The advantage of MBE grown $\mathrm{Mg}$-doped $\mathrm{GaN}$ is that $\mathrm{Mg}-\mathrm{H}$ complexes are less likely to form as there are no carrier gases used in this growth technique. However, MBE is not a scalable method for mass production of LEDs due to low growth rates and the long cycle times required to achieve an ultra-high vacuum; in contrast MOCVD is not limited by these factors. There has only been one report discussing the effects of annealing on MOCVD grown $\mathrm{Mg}$ doped $\mathrm{zb}-\mathrm{GaN}^{17}$. In this paper, the effects of pulsed laser annealing on its own and in combination with rapid thermal annealing on the room temperature optical properties of $\mathrm{Mg}$-doped $\mathrm{zb}-\mathrm{GaN}$ were studied $^{17}$.

In this work, we investigate the effect of conventional thermal annealing in a $\mathrm{N}_{2}$ atmosphere on the optical properties of Mg-doped zb-GaN epilayers grown by MOCVD on 3C-SiC/Si substrates. Firstly, the $\mathrm{Mg}$ concentration, temperature and excitation power dependence of the PL spectra are used to identify the features associated with Mg-doping. The effect of annealing on the features is then studied using steady-state and time-resolved PL measurements.

\section{Experimental Method}

The GaN epilayers were grown by MOCVD in a 6x2" Thomas Swan close-coupled showerhead reactor on $2 \times 2 \mathrm{~cm}^{2}$ pieces of a $150 \mathrm{~mm}$ diameter (001) 3C-SiC/Si substrate provided by Anvil Semiconductors Ltd. The substrate consists of a $2.7 \mu \mathrm{m}$ thick layer of 3C$\mathrm{SiC}$ grown on a $1.00 \mathrm{~mm}$ thick $\mathrm{Si}$ wafer with $4^{\circ}$ miscut towards the [110] in-plane direction. Note that the lattice mismatch between zb-GaN and $3 \mathrm{C}-\mathrm{SiC}$ is $3.4 \%{ }^{23}$. A GaN nucleation layer was first grown followed by $\sim 300 \mathrm{~nm} \mathrm{GaN}$ and $\sim 400 \mathrm{~nm}$ thick $\mathrm{GaN}: \mathrm{Mg}$ epilayers. The $\mathrm{Ga}, \mathrm{Mg}$ and $\mathrm{N}$ sources were trimethylgallium (TMG), bis-(cyclopentadienyl)magnesium(II) $\left(\mathrm{Cp}_{2} \mathrm{Mg}\right)$ and ammonia $\left(\mathrm{NH}_{3}\right)$, respectively, and hydrogen was used as the carrier gas, while nitrogen gas was used during the thermal annealing step. Further growth details can be found elsewhere ${ }^{24}$. The microstructure of samples grown by this method has previously been studied in detail ${ }^{25}$, where it was shown that stacking faults are the dominant defect, having a density of order $10^{5} \mathrm{~cm}^{-1}$. Moreover, these stacking faults can propagate to the surface, causing significant roughening ${ }^{26}$. Two sets of samples were grown. The first set consisted of a nominally undoped $\mathrm{zb}-\mathrm{GaN}$ epilayer and two Mg-doped samples both annealed in $\mathrm{N}_{2}$ atmosphere post-growth at a temperature of $740^{\circ} \mathrm{C}$ for $1200 \mathrm{~s}$. The $\mathrm{Mg}$-doped samples were identical except for the Mg flow rate during growth, resulting in $\mathrm{Mg}$ concentrations of $8.6 \times 10^{18} \mathrm{~cm}^{-3}$ and $1.9 \times 10^{19} \mathrm{~cm}^{-3}$, as determined by secondary ion mass spectrometry (SIMS). The higher of these $\mathrm{Mg}$ concentrations is similar to that used in previous investigations of Mg-doped wz-GaN ${ }^{10,11}$, whilst the lower value results in PL spectra with more easily identifiable features, as will be seen below. The second sample set consisted of $\mathrm{Mg}$ doped samples with the same concentration of $1.7 \times 10^{19} \mathrm{~cm}^{-3}$ but with only one sample thermally annealed (also in the reactor postgrowth in a $\mathrm{N}_{2}$ atmosphere at $740^{\circ} \mathrm{C}$ for $1200 \mathrm{~s}$ ). The $\mathrm{Mg}$ concentrations investigated here are similar to those investigated in refs 18 and 20, but lower by about an order of magnitude than the samples used in ref 17 . 
The SIMS analysis was performed commercially by Evans Analytical Group Laboratories and measured the concentration of $\mathrm{Mg}$ using a negative oxygen ion beam. X-ray diffraction (XRD) measurements were carried out using a PANalytical Empyrean diffractometer, equipped with $\mathrm{Cu}-\mathrm{K} \alpha 1$ source, 2-bounce hybrid monochromator, and PIXcel solid state area detector. The optical properties of the samples were investigated using PL measurements to probe the carrier-dopant interactions. Steady-state PL measurements were obtained using a continuous wave (cw) $\mathrm{HeCd}$ laser emitting at $325 \mathrm{~nm}(3.8 \mathrm{eV})$ to excite the sample above the $\mathrm{zb}-\mathrm{GaN}$ bandgap (3.3 eV at low temperature $\left.{ }^{6}\right)$. The sample temperature was controlled by attaching the samples onto the cold finger of a closed cycle He cryostat. The emission was collected by a spectrometer with resolution $\leq 5 \mathrm{~nm}$ and passed onto a cooled photomultiplier tube. The measured spectra were corrected for the system response using a calibrated black body source. Uniformity across a sample was checked by comparing spectra collected from different positions; no significant difference in these spectra was observed, as shown in S1 of the supplementary material.

Time-resolved measurements were obtained using time correlated single photon counting (TCSPC) with pulsed excitation from a frequency tripled $80 \mathrm{MHz}$ Ti-sapphire laser (wavelength $266 \mathrm{~nm}$ ) to excite the samples above the zb-GaN bandgap. A cooled microchannel plate with a temporal resolution of $70 \mathrm{ps}$ was used to detect the incoming single photons.

\section{Experimental Results}

\section{PL dependence on Mg concentration}

The Mg concentration dependence of the $10 \mathrm{~K}$ PL spectrum is shown in figure 1, where all spectra have been normalised to the peak intensity. The undoped sample has three near band edge (NBE) peaks at $3.23 \mathrm{eV}, 3.11 \mathrm{eV}$ and $3.05 \mathrm{eV}$, and there is also a broad band centred at $\sim 2.9 \mathrm{eV}$. The spectral shifts of these features with both temperature and excitation power density, as shown in figures S3 and S4 of the supplementary material (SM) respectively, allow the recombination processes associated with each to be identified. Thus, the peak at $3.23 \mathrm{eV}$ is attributed to recombination of donor bound excitons $\left(\mathrm{D}^{0} \mathrm{X}\right)$, whilst the $3.11 \mathrm{eV}$ and $2.9 \mathrm{eV}$ peaks are attributed to donor-acceptor pair recombination (DAP) and the $3.05 \mathrm{eV}$ peak is attributed to recombination between an electron in the conduction band and a hole at the acceptor level $\left(\mathrm{e}, \mathrm{A}^{0}\right)$, consistent with previous work $^{27}$. It has been reported elsewhere that the band around $2.9 \mathrm{eV}$ is formed of two separate DAP peaks ${ }^{27}$. Therefore, the lower energy shoulder at $2.82 \mathrm{eV}$ is attributed to a separate DAP recombination; the band as a whole is likely to be composed of a number of overlapping peaks corresponding to different types of donor and acceptor.

Figure 1 also shows that when $\mathrm{zb}-\mathrm{GaN}$ is doped with $\mathrm{Mg}$ to $8.6 \times 10^{18} \mathrm{~cm}^{-3}$, the two DAP peaks at $2.82 \mathrm{eV}$ and $2.9 \mathrm{eV}$ are replaced by a broad blue emission band centred around $2.9 \mathrm{eV}$ which grows in intensity relative to the other spectral features. Increasing the $\mathrm{Mg}$ concentration further to $1.9 \times 10^{19} \mathrm{~cm}^{-3}$ causes the relative intensity of the NBE emission to drop even more and is replaced by a weak and broad emission centred just below $3.2 \mathrm{eV}$. This feature likely results from the merging of the $\mathrm{D}^{0} \mathrm{X}$ peak with a peak associated with $\mathrm{Mg}$ doping previously reported, which has been designated as the 'ultraviolet luminescence' (UVL) band and attributed to either DAP recombination between a shallow donor and the $\mathrm{Mg}$ acceptor or $\left(\mathrm{e}, \mathrm{A}^{0}\right)$ with $\mathrm{Mg}$ as the acceptor $^{15,28,29}$.

The broad emission around $2.9 \mathrm{eV}$ evident for $\mathrm{zb}-\mathrm{GaN}$ after $\mathrm{Mg}$-doping has been reported previously and referred to as the 'blue band" ${ }^{18-}$ ${ }^{20,22}$. The NBE peaks were also reported to disappear as the $\mathrm{Mg}$ concentration increases for MBE grown Mg-doped zb-GaN ${ }^{20}$. It has been previously suggested that the blue band emission in MBE grown Mg-doped $\mathrm{zb}-\mathrm{GaN}$ was similar to that seen in $\mathrm{Mg}$-doped wz-GaN ${ }^{18}$, with the emission due to DAP recombination between a shallow $\mathrm{Mg}_{\mathrm{Ga}}$ acceptor and $\mathrm{V}_{\mathrm{N}}-\mathrm{Mg}$ complex acting as a deep donor $^{13}$. The peak shifts we observe for increasing temperature and excitation power density, as shown in the SM, confirm that this 
is a feature associated with DAP recombination. The blue band peak position is similar for both the $\mathrm{wz}$ and $\mathrm{zb}$ crystal phases despite the change in the bandgap energy. This indicates that the change in bandgap energy is compensated by a change in another parameter associated with DAP recombination. Theoretical studies have suggested that the same donor in both crystal phases of $\mathrm{GaN}$ have similar ionisation energies ${ }^{30,31}$ and ref 22 shows the $\mathrm{Mg}$ ionisation energy is again similar between the two crystal phases using both optical and electrical measurements ${ }^{22}$. This suggests a change in the average separation between donors and acceptors in the different crystal phases or another donor is responsible for the blue band recombination in $\mathrm{Mg}$-doped $\mathrm{zb}-\mathrm{GaN}$. The temperature and power density dependent peak shifts of the $3.23 \mathrm{eV}$ peak are consistent with $\mathrm{D}^{0} \mathrm{X}$ recombination, as they were for the undoped sample - see SM. A weak peak at $3.35 \mathrm{eV}$, i.e. above the bandgap of $\mathrm{zb}-\mathrm{GaN}$, is present in the PL of all samples investigated and is attributed to small amounts of wz-inclusions in the zb-GaN crystal matrix. However, the intensity of this emission is two orders of magnitude lower than the dominant recombination features in the spectrum, indicating wz-inclusions have little effect on the optical properties of the samples.

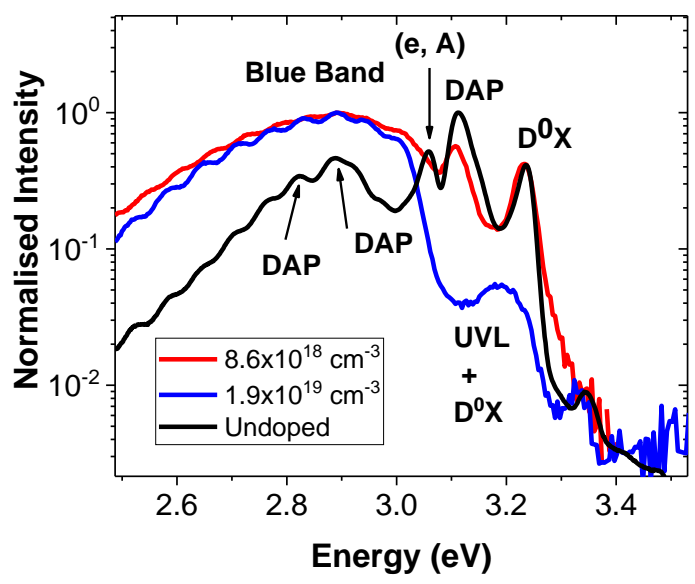

Figure 1. Normalised $10 \mathrm{~K}$ PL comparison of nominally undoped and annealed $\mathrm{Mg}$-doped $\mathrm{zb}-\mathrm{GaN}$ samples. Samples were excited at a cw power density of $10 \mathrm{Wcm}^{-2}$.

\section{Thermally Annealed Mg-doped zb- GaN}

Figure 2 compares the $10 \mathrm{~K}$ PL spectra of the annealed and unannealed Mg-doped zb-GaN epilayers. The blue band is the dominant feature in both spectra, but NBE peaks are also evident and change after annealing. For the unannealed sample, the NBE is composed of a merged UVL band and $\mathrm{D}^{0} \mathrm{X}$ peak, with the latter evident as a high energy shoulder at $3.23 \mathrm{eV}$. There is also evidence of a small peak located above the bandgap of $\mathrm{zb}-\mathrm{GaN}(3.3 \mathrm{eV})$ that is attributed to very small amounts of wz inclusions in the zb-GaN crystal matrix, in agreement with XRD measurements of the phase purity (see SM). The UVL band is significantly suppressed in the annealed spectrum obtained at $10 \mathrm{Wcm}^{-2}$ and the $\mathrm{D}^{0} \mathrm{X}$ peak is clearly defined again (however, as shown in figure S8, the UVL band is more evident at low power densities.) The suppression of the UVL band in Figure 2 after thermal annealing suggests that it is associated with $\mathrm{Mg}-\mathrm{H}$ complexes. The NBE PL spectrum of the annealed sample in Figure 2 differs from that of the high $\mathrm{Mg}$-doped sample shown in Figure 1 when both are excited at $10 \mathrm{Wcm}^{-2}$, with the former retaining a distinct $\mathrm{D}^{0} \mathrm{X}$ peak. However, the two spectra become similar as the excitation power density is reduced further (see figure S9), consisting in both cases of merged UVL and $\mathrm{D}^{0} \mathrm{X}$ peaks, which illustrates the sensitivity of the NBE PL to the interplay between $\mathrm{Mg}$ concentration and excitation power density. Figure 2 also shows that the peak intensity of the blue band emission is increased significantly after annealing, by a factor of $\sim 5$. Similar behaviour has been observed in wz-GaN samples and attributed to the reduction in the density of $\mathrm{Mg}-\mathrm{H}$ complexes by the annealing process ${ }^{9,15}$. Ref 17 reports an increase of the blue emission intensity (which itself is part of a broader emission feature) in the room temperature PL after pulsed laser annealing (PLA) of MOCVD grown Mg-doped $\mathrm{zb}-\mathrm{GaN}^{17}$, which was attributed to the separation of $\mathrm{Mg}-\mathrm{H}$ related complexes passivating the Mg-related deep donors. However, further rapid thermal annealing at $850^{\circ} \mathrm{C}$ for $3 \mathrm{~min}$ of the same epilayers resulted 
in the reduction of the emission intensity ${ }^{17}$, in contrast to the increase in blue band emission obtained by the longer duration thermal annealing employed in our study. This behaviour was attributed to the PLA not resulting in the removal of the dissociated $\mathrm{H}$ from the $\mathrm{Mg}$-doped layer due to the short timescale of the laser pulses, and thus allowing the $\mathrm{Mg}-\mathrm{H}$ complexes to reform during the subsequent rapid annealing stage ${ }^{17}$.

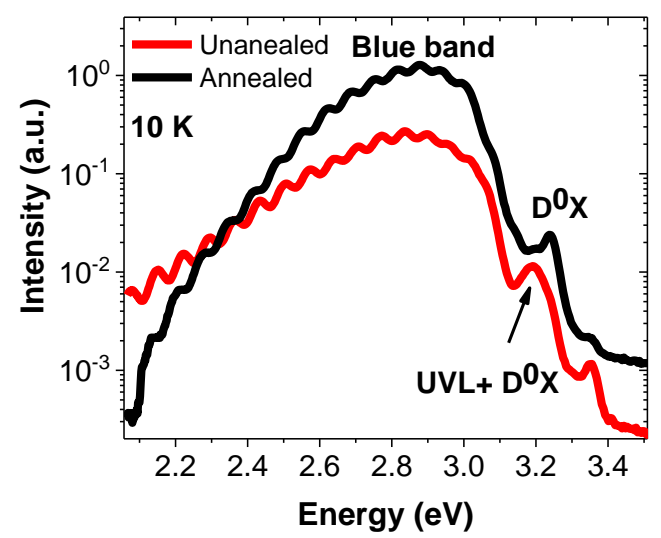

Figure $210 \mathrm{~K}$ PL comparison of $\mathrm{Mg}$ doped $\mathrm{zb}-\mathrm{GaN}$ samples with $[\mathrm{Mg}]=1.7 \times 10^{19} \mathrm{~cm}^{-3}$ before and after annealing in $\mathrm{N}_{2}$. Samples were excited with a $\mathrm{cw}$ power density of $10 \mathrm{Wcm}^{-2}$.

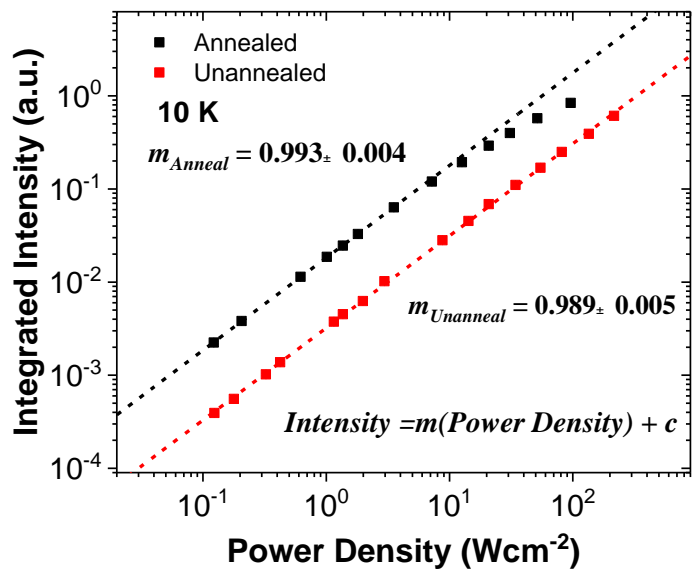

Figure 3. Spectrally integrated intensity of the blue band emission as a function of the $\mathrm{cw}$ power density for both annealed and unannealed samples $\left([\mathrm{Mg}]=1.7 \times 10^{19} \mathrm{~cm}^{-3}\right)$. The data points are fit with a straight fit.

Figure 3 shows the spectrally-integrated intensity of the blue band as a function of the excitation power density, with the data fit with a straight line. The unannealed sample shows a linear relationship between intensity and excitation power density that does not change, even at the highest power densities shown here.
After annealing, in contrast, two distinct regions can be observed in the figure. For power densities up to $3.5 \mathrm{Wcm}^{-2}$ there is a linear increase in intensity as power density increases similar to the unannealed sample. As the power density is increased above $3.5 \mathrm{Wcm}^{-2}$, however, the intensity exhibits a sublinear relationship indicating that the blue band emission from the annealed sample is saturating. An increase in the density of optically active $\mathrm{Mg}$ acceptors following annealing might be expected to increase the saturation intensity of the blueband. However, since under cw excitation the steady-state carrier density increases with the recombination lifetime, a significant increase in this lifetime could increase the carrier density sufficiently to more than compensate for the increased acceptor density, resulting in the saturation behaviour observed.

To investigate this further, low temperature time-resolved PL measurements were carried out on the annealed and unannealed samples, and the resulting decay transients are shown in Figure 4. The decays consist of an initial fast component followed by a second slow component that, as shown in the inset, persists to the sub-millisecond time scale. Similar decays have been reported previously for $\mathrm{Mg}$ doped wz-GaN ${ }^{32-34}$. It can be seen from Figure 4 the intensity of the blue band decays much more quickly prior to annealing; dropping to 1/e of the initial intensity in $\sim 5.2 \mathrm{~ns}$ compared to $\sim 21$ ns after annealing. Similar behaviour is seen for emission energies across the blue band as shown in section S3 of the supplementary material in greater detail. The decays can be described by a combination of single and stretched exponential (as shown in section S3). The stretched exponential, describing the long tail of the decay, is governed by the dispersion factor $\delta$, which describes the level of disorder in the system ${ }^{35}$. The value of $\delta$ is in the range $0<$ $\delta<1$, with $\delta=1$ corresponding to complete order, and $\delta=0$ corresponding to complete disorder. As shown in $\mathrm{S} 3$ the value of $\delta$ increases upon annealing, suggesting a decrease in disorder. The different values of $\delta$ between the annealed and unannealed samples results in the tails of the decays intersecting (at $\sim 800 \mathrm{~ns}$ in Figure 4) and the smaller $\delta$ value of the 
unannealed sample leads to its tail persisting to later times, as shown in the inset of Figure 4.

The radiative lifetime of the blue band emission will decrease following annealing since the higher density of active $\mathrm{Mg}$ dopants (i.e. freed from the $\mathrm{Mg}-\mathrm{H}$ complex) that this produces will decrease the average separation between the donors and acceptors. Since annealing produces an increase of the overall PL lifetime then this suggests that there is a greater increase in the non-radiative lifetime associated with the blue band. A reduction in the non-radiative recombination in $\mathrm{Mg}$ implanted wz-GaN samples has also been reported following annealing based on photothermal deflection measurements ${ }^{12}$, and attributed to the reduced density of $\mathrm{V}_{\mathrm{N}}-\mathrm{V}_{\mathrm{Ga}}$ complexes after annealing. It should be noted that the samples investigated in ref 12 were annealed at temperatures in the range $1000-1300^{\circ} \mathrm{C}$ for $5 \mathrm{mins}$ to recover the damage inflicted from ion implantation of the Mg.

XRD measurements (see SM) show that thermal annealing, under the conditions used in this paper, had no significant effect on the reciprocal space maps and intensity profiles along stacking fault streaks. Meaning both the phase purity and planar structural defects are unaffected by the annealing process. Thus the decrease in non-radiative recombination is unlikely to be caused by planar defects such as stacking faults, which have been suggested to act as centres of non-radiative recombination in $\mathrm{zb}-\mathrm{GaN}^{36}$ and are the dominant defect in zb$\mathrm{GaN}$ epilayers ${ }^{25}$. However, these XRD profiles do not provide information on lower dimensional defects such as threading dislocations (1D) and point defects (0D). Therefore, the dominant non-radiative recombination mechanisms in Mg-doped $\mathrm{zb}$ $\mathrm{GaN}$ are likely associated with these.

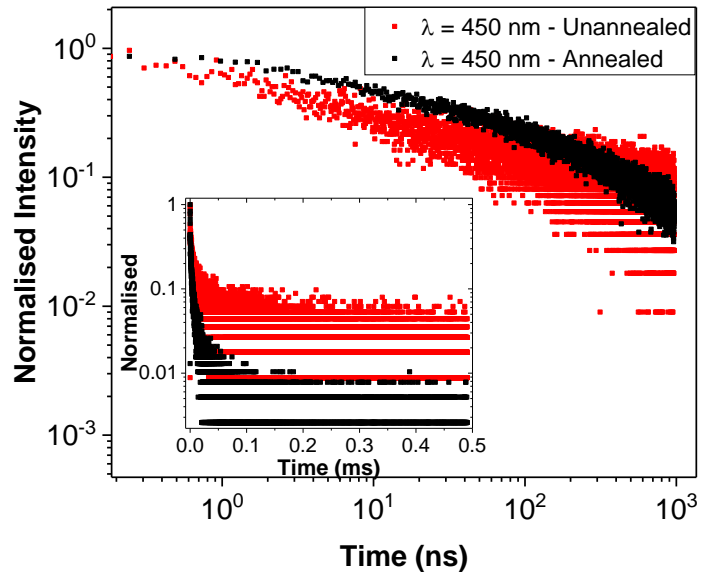

Figure 4. PL decay transients for the annealed and unannealed $\mathrm{Mg}$ doped zb-GaN samples $\left([\mathrm{Mg}]=1.7 \times 10^{19} \mathrm{~cm}^{-3}\right)$ taken at a temperature of $10 \mathrm{~K}$ and at a wavelength of $450 \mathrm{~nm}$, corresponding to the peak of the blue band emission in both samples. The inset shows the decays up to $0.5 \mathrm{~ms}$.

\section{Conclusion}

In summary, the effect of thermal annealing on the optical properties of $\mathrm{Mg}$ doped $\mathrm{zb}-\mathrm{GaN}$ grown on $3 \mathrm{C}-\mathrm{SiC} / \mathrm{Si}$ (001) substrates by MOCVD has been investigated. A blue band was observed in the spectrum, which is associated with $\mathrm{Mg}$ doping. A significant increase in the intensity of this blue band (by a factor of 5) was observed when thermal annealing of the Mg-doped zb-GaN epilayers was carried out (at $740{ }^{\circ} \mathrm{C}$ in $\mathrm{N}_{2}$ for $20 \mathrm{~min}$ ), as previously observed for $\mathrm{Mg}$-doped $\mathrm{GaN}$ in the wurtzite phase. Power density dependent measurements show that a lower saturation power density is observed for this emission band after annealing, and PL time decay measurements show that the recombination lifetime is significantly increased after annealing. It is thus concluded that thermal annealing both increases the density of active $\mathrm{Mg}$ dopants, thereby improving p-type conductivity, and decreases the density of non-radiative recombination centres in Mg-doped zb-GaN epilayers, in agreement with what is observed in Mg-doped wz-GaN.

\section{Supplementary Material}

See the supplementary material for XRD data, peak shifts with temperature and excitation power that identify spectral features of the samples and further analysis of the blue band decay transients. 


\section{Acknowledgements}

The authors would like to acknowledge funding from the Engineering and Physics Sciences Research Council (EPSRC) for a studentship (Dyer) and for support under grant codes EP/R010250/1 and EP/R01146X/1. D. J. Wallis would like to acknowledge support through EPSRC fellowship EP/N01202X/2. The authors would also like to thank Dr Peter Mitchell for helpful discussions on this work.

\section{Data Availability}

The datasets that support the findings of this study are openly available in the University of Manchester repository

http://doi.org/10.48420/14627817

\section{References}

${ }^{1}$ M. Auf Der Maur, A. Pecchia, G. Penazzi, W. Rodrigues, and A. Di Carlo, Phys. Rev. Lett. 116, 027401 (2016).

${ }^{2}$ M.H. Crawford, IEEE J. Sel. Top. Quant. 15, 1028 (2009).

${ }^{3}$ B. Ding, Mater. Sci. Technol. 34, 1615 (2018).

${ }^{4}$ S. Hammersley, M.J. Kappers, F.C.P. Massabuau, S.-L. Sahonta, P. Dawson, R.A. Oliver, and C.J. Humphreys, Phys. Status Solidi 13, 209 (2016).

${ }^{5}$ D.J. As, Microelectronics J. 40, 204 (2009).

${ }^{6}$ I. Vurgaftman and J.R. Meyer, J. Appl. Phys. 94, 3675 (2003).

${ }^{7}$ D.R. Elsaesser, M.T. Durniak, A.S. Bross, and C. Wetzel, J. Appl. Phys. 122, 115703 (2017).

${ }^{8}$ M.A. Reshchikov, P. Ghimire, and D.O. Demchenko, Phys. Rev. B 97, 205204 (2018).

${ }^{9}$ S. Nakamura, N. Iwasa, M. Senoh, and T. Mukai, Jpn. J. Appl. Phys. 31, 1258 (1992).

${ }^{10}$ A. Castiglia, J.-F. Carlin, and N. Grandjean, Appl. Phys. Lett. 98, 213505 (2011).
${ }^{11}$ A. Klump, M.P. Hoffmann, F. Kaess, J. Tweedie, P. Reddy, R. Kirste, Z. Sitar, and R. Collazo, J. Appl. Phys. 127, 045702 (2020).

${ }^{12}$ M. Sumiya, K. Fukuda, S. Takashima, S. Ueda, T. Onuma, T. Yamaguchi, T. Honda, and A. Uedono, J. Cryst. Growth 511, 15 (2019).

${ }^{13}$ U. Kaufmann, M. Kunzer, M. Maier, H. Obloh, A. Ramakrishnan, B. Santic, and P. Schlotter, Appl. Phys. Lett. 72, 1326 (1998).

${ }^{14}$ S.F. Chichibu, K. Shima, K. Kojima, S. Takashima, M. Edo, K. Ueno, S. Ishibashi, and A. Uedono, Appl. Phys. Lett. 112, 211901 (2018).

${ }^{15}$ F. Shahedipour and B.W. Wessels, Appl. Phys. Lett. 76, 3011 (2000).

${ }^{16}$ H. Amano, M. Kito, K. Hiramatsu, and I. Akasaki, Jpn. J. Appl. Phys. 28, L2112 (1989).

${ }^{17}$ D. Xu, H. Yang, S.. Li, D.. Zhao, H. Ge, and R.. Wu, J. Cryst. Growth 209, 203 (2000).

${ }^{18}$ R.E.L. Powell, S. V. Novikov, C.T. Foxon, A. V. Akimov, and A.J. Kent, Phys. Status Solidi C. 11, 385 (2014).

${ }^{19}$ D.J. As, T. Simonsmeier, B. Schöttker, T. Frey, D. Schikora, W. Kriegseis, W.

Burkhardt, and B.K. Meyer, Appl. Phys. Lett. 73, 1835 (1998).

${ }^{20}$ E. Martinez-Guerrero, B. Daudin, G. Feuillet, H. Mariette, Y. Genuist, S. Fanget, A. Philippe, C. Dubois, C. Bru-Chevallier, G. Guillot, P. Aboughe Nze, T. Chassagne, Y. Monteil, H. Gamez-Cuatzin, and J. Tardy, Mater. Sci. Eng. B 82, 59 (2001).

${ }^{21}$ D. Xu, H. Yang, D.G. Zhao, S.F. Li, and R.H. Wu, J. Appl. Phys. 87, 2064 (2000).

22 D.J. As, Phys. Status Solidi B 210, 445 (1998).

${ }^{23}$ H. Okumura, K. Ohta, G. Feuillet, K. Balakrishnan, S. Chichibu, H. Hamaguchi, P. Hacke, and S. Yoshida, J. Cryst. Growth 178, 113 (1997).

${ }^{24}$ L.Y. Lee, M. Frentrup, M.J. Kappers, R.A. Oliver, C.J. Humphreys, and D.J. Wallis, J. Appl. Phys. 124, 105302 (2018).

${ }^{25}$ L.Y. Lee, M. Frentrup, P. Vacek, M.J. Kappers, D.J. Wallis, and R.A. Oliver, J. Appl. 
Phys. 125, 105303 (2019).

${ }^{26}$ B. Ding, M. Frentrup, S.M. Fairclough, M.J. Kappers, M. Jain, A. Kovács, D.J. Wallis, and R.A. Oliver, J. Appl. Phys. 128, 145703 (2020).

${ }^{27}$ D. Xu, H. Yang, J.B. Li, D.G. Zhao, S.F. Li, S.M. Zhuang, R.H. Wu, Y. Chen, and G.H. Li, Appl. Phys. Lett. 76, 3025 (2000).

${ }^{28}$ M.A. Reshchikov and H. Morkoç, J. Appl. Phys. 97, 061301 (2005).

${ }^{29}$ M.A. Reshchikov, J. Appl. Phys. 127, 055701 (2020).

${ }^{30}$ F. Mireles and S.E. Ulloa, Appl. Phys. Lett. 74, 248 (1999).

${ }^{31}$ H. Wang and A.-B. Chen, J. Appl. Phys. 87, 7859 (2000).

${ }^{32}$ M. Godlewski, T. Suski, I. Grzegory, S.
Porowski, J.. Bergman, W.. Chen, and B. Monemar, Phys. B Condens. Matter 273-274, 39 (1999).

${ }^{33}$ Y.-H. Kwon, S.K. Shee, G.H. Gainer, G.H. Park, S.J. Hwang, and J.J. Song, Appl. Phys. Lett. 76, 840 (2000).

${ }^{34}$ F. Shahedipour and B.W. Wessels, MRS Internet J. Nitride Semicond. Res. 6, e12 (2001).

${ }^{35}$ S.A. Church, B. Ding, P.W. Mitchell, M.J. Kappers, M. Frentrup, G. Kusch, S.M.

Fairclough, D.J. Wallis, R.A. Oliver, and D.J. Binks, Appl. Phys. Lett. 117, 032103 (2020).

${ }^{36}$ R.M. Kemper, P. Veit, C. Mietze, A. Dempewolf, T. Wecker, F. Bertram, J. Christen, J.K.N. Lindner, and D.J. As, Phys. Status Solidi 12, 469 (2015). 

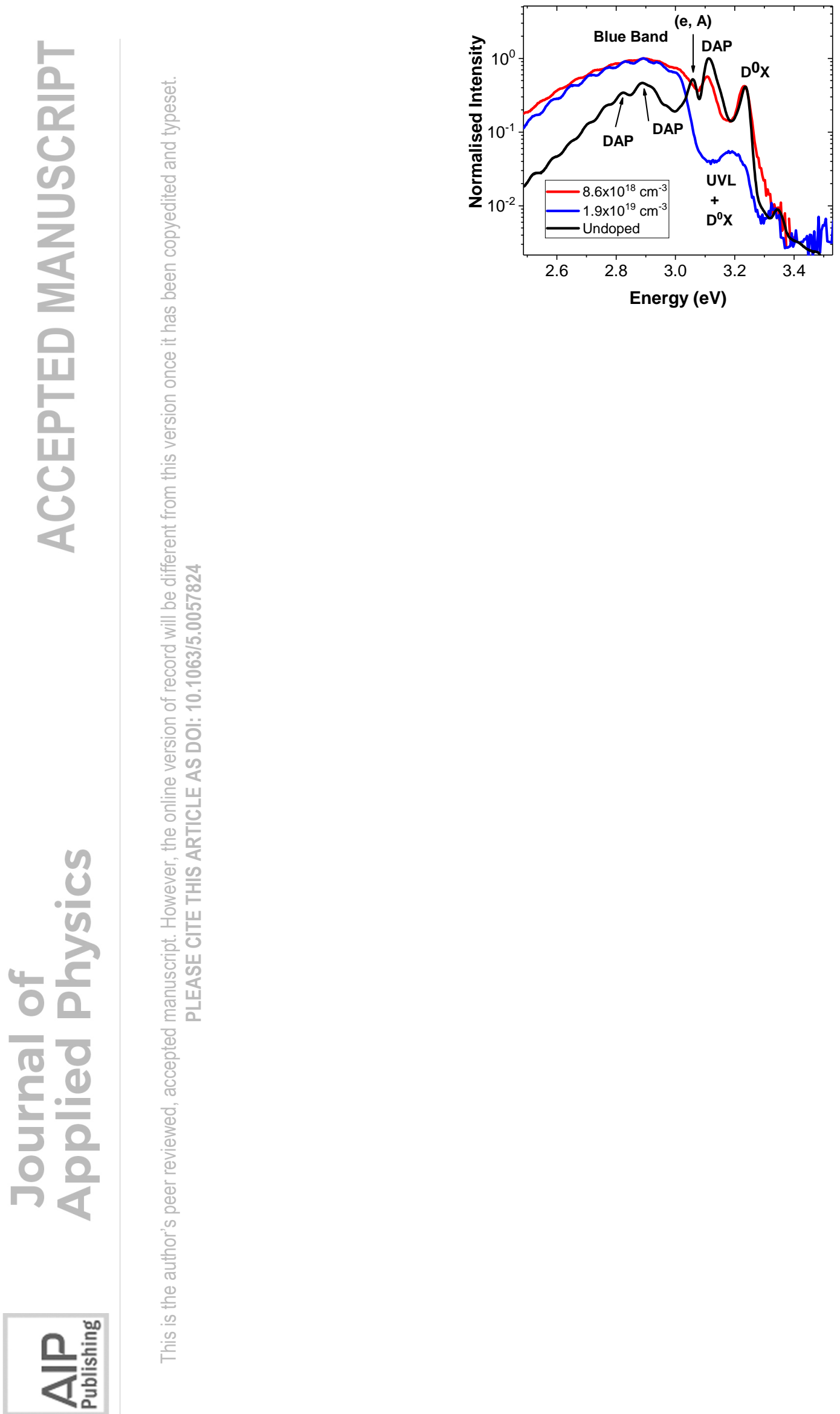

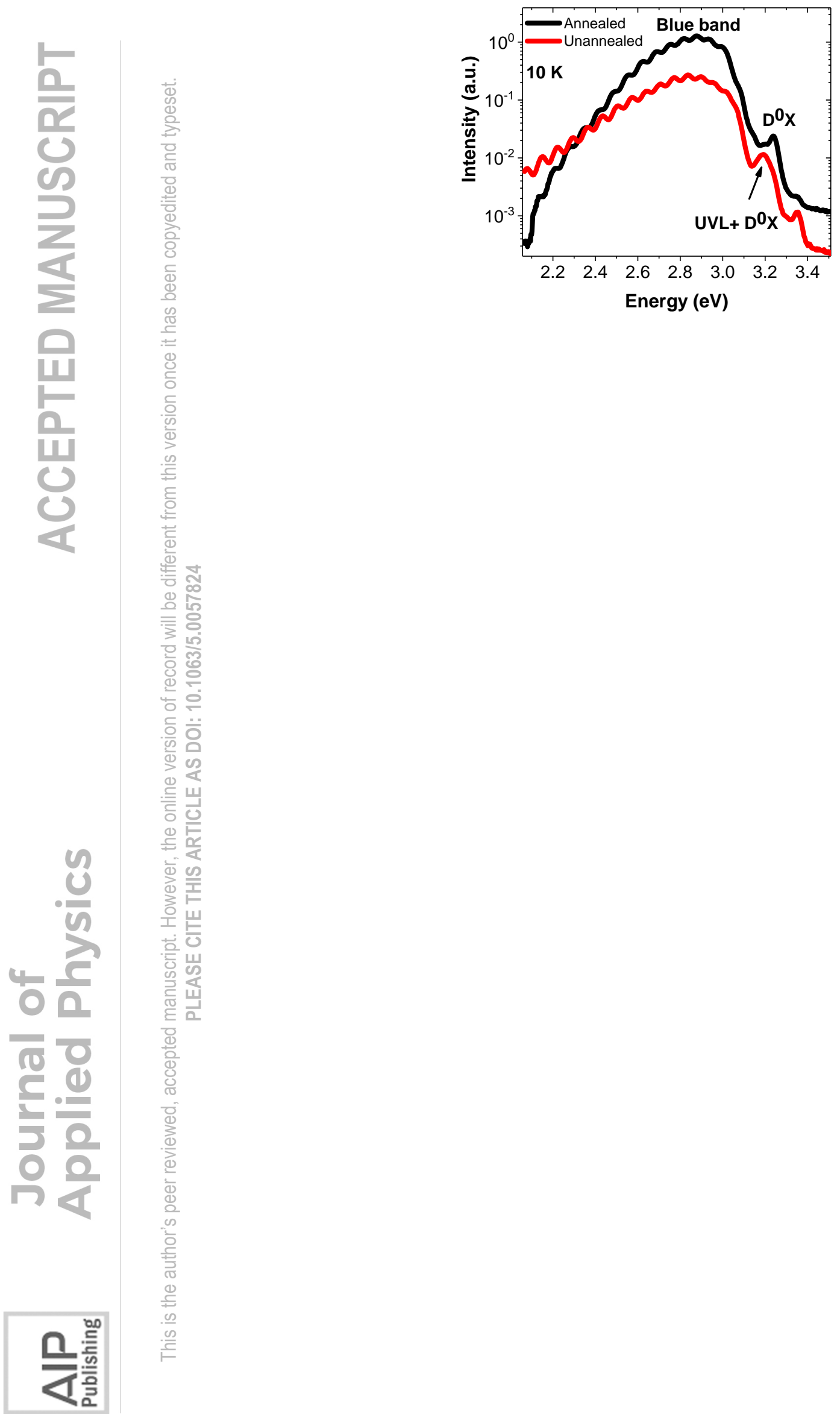

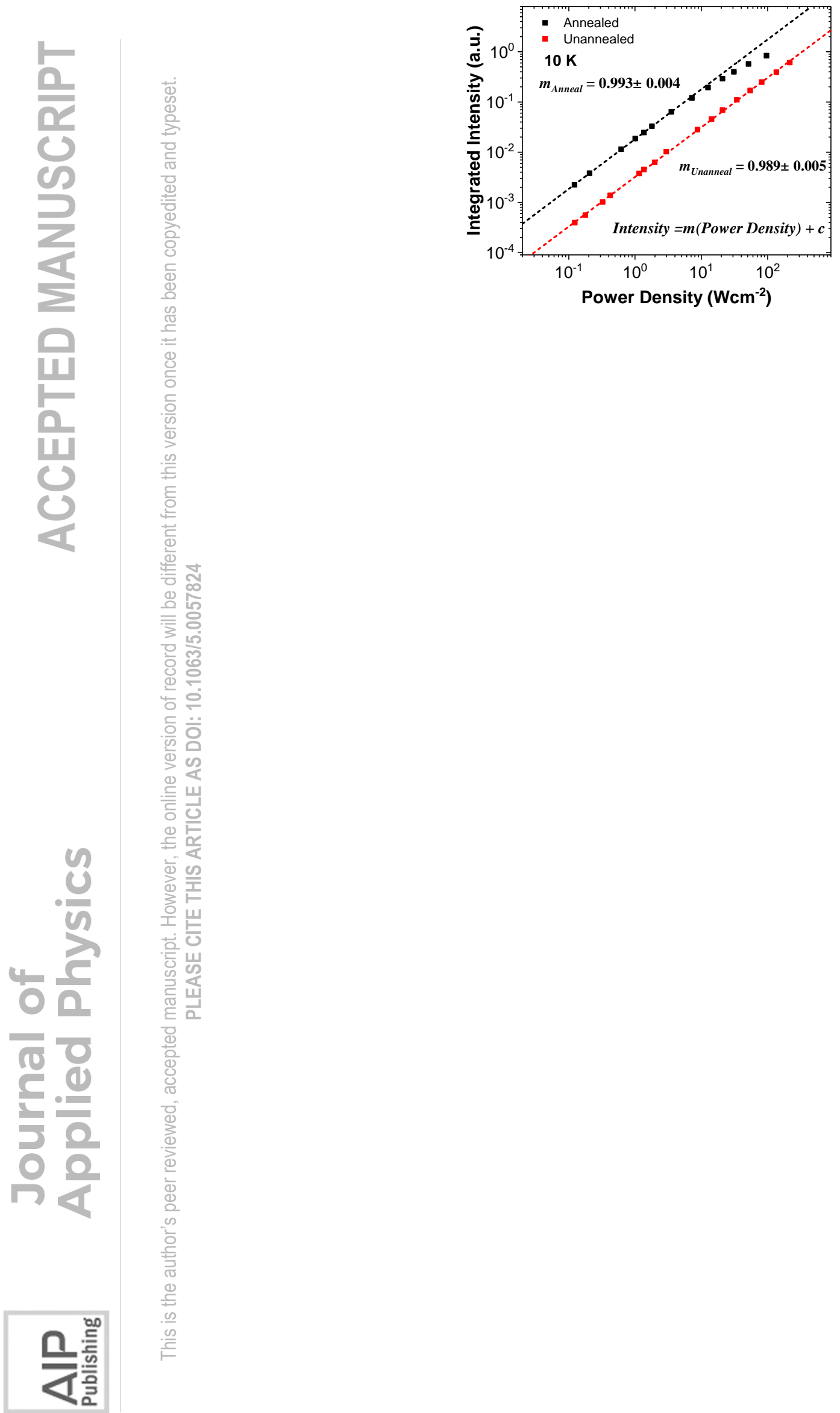

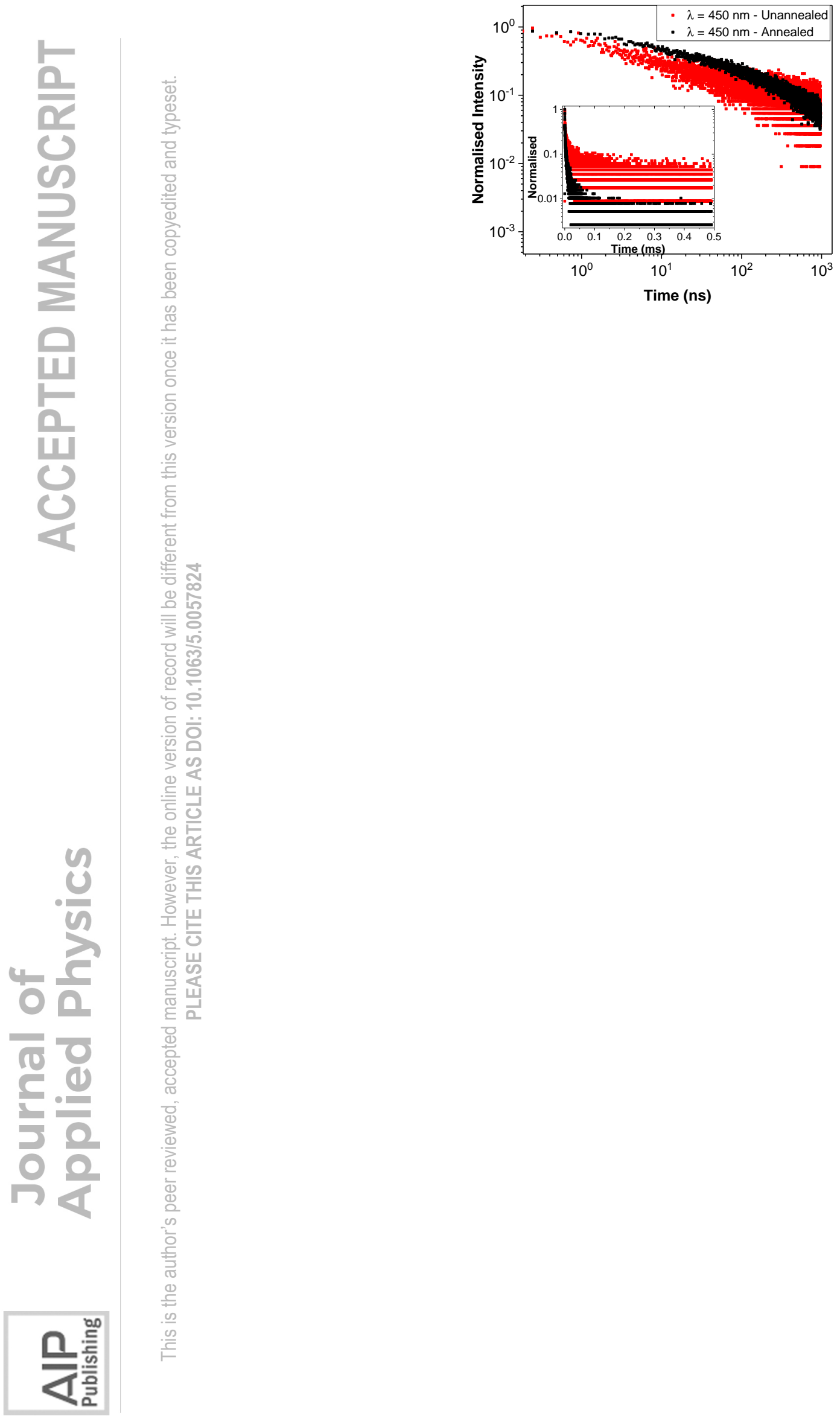